\title{
Intervenções psicológicas no processo de aposentadoria: revisão integrativa da literatura brasileira
}

\author{
Psychological interventions in the retirement process: an integrative review of \\ Brazilian literature
}

\section{Intervenciones psicológicas en el proceso de jubilación: una revisión integradora de la literatura brasileña}

\author{
Natalí Andrade da Cunha \\ Universidade Federal do Triângulo Mineiro (UFTM) \\ Fabio Scorsolini-Comin ${ }^{1}$ \\ Universidade de São Paulo (USP) \\ Raquel Cornélio Marin \\ Universidade Federal do Triângulo Mineiro (UFTM)
}

\begin{abstract}
Resumo
Introdução: A aposentadoria representa uma fase de transição, com importantes repercussões para a vida do indivíduo em suas diferentes dimensões, como carreira, saúde, família e socialização. As intervenções psicológicas pré e pós-aposentadoria objetivam contribuir nessa transição, promovendo bem-estar, adaptação e maior qualidade de vida no enfrentamento das mudanças inerentes a essa etapa desenvolvimental. Objetivo: Este estudo de revisão integrativa teve por objetivo conhecer o panorama das intervenções psicológicas utilizadas nos processos de pré e pósaposentadoria no Brasil. Método: A questão norteadora foi: qual o perfil das intervenções psicológicas no contexto da aposentadoria em termos de características, resultados e recomendações no Brasil? A partir das bases de dados LILACS, SciELO, PePSIC e PsycINFO, foram realizadas buscas no período de 2002 a 2017. Resultados e Discussões: Foram recuperados dez artigos, sendo cinco empíricos e cinco teóricos. A maioria tem o objetivo de descrever a importância dos programas de preparação para a aposentadoria (PPA). As intervenções atingiram mais o público feminino e buscaram promover o bemestar a partir da exploração das perdas, dos ganhos e das mudanças ocorridas nessa fase. Conclusão: Recomenda-se a participação de psicólogos nesses programas, bem como a avaliação longitudinal das propostas existentes, buscando seu aperfeiçoamento constante.
\end{abstract}

Palavras-chave: aposentadoria, profissão, envelhecimento, psicoterapia

\begin{abstract}
Introduction: Retirement represents a transition phase with important repercussions for the life of the individual in its different dimensions, such as career, health, family, and socialization. Pre and post-retirement psychological interventions aim to contribute to this transition, promoting wellbeing, adaptation and higher quality of life in facing the changes inherent to this developmental stage. Objective: This integrative review study aims to discover the panorama of the psychological interventions used in the processes of pre and post retirement in Brazil. Method: The guiding question was: what is the profile of psychological interventions of retirement in terms of characteristics, results, and recommendations? From the LILACS, SciELO, PePSIC, and PsycINFO databases, searches were carried out in the period of 2002 through 2017. Results and Discussion: Ten articles were retrieved, five being empirical and five theoretical. Most aim to describe the importance of retirement preparation programs (PPA, in Portuguese). The interventions affected the female audience more and sought to promote well-being by exploiting the losses, gains, and changes that occurred at that stage. Conclusion: It is recommended that psychologists participate in these programs, as well as the longitudinal evaluation of existing proposals, seeking constant improvement.
\end{abstract}

Keywords: retirement, profession, aging, psychotherapy

\footnotetext{
${ }^{1}$ Endereço de contato: Escola de Enfermagem de Ribeirão Preto da Universidade de São Paulo, Avenida Bandeirantes, 3900, Monte Alegre, Ribeirão Preto, SP, CEP: 14040-902. Telefone: (16) 3315-0535. E-mail: fabio.scorsolini@usp.br
} 


\section{Resumen}

Introducción: La jubilación representa una fase de transición, con importantes repercusiones para la vida del individuo en sus diferentes dimensiones, como carrera, salud, familia y socialización. Las intervenciones psicológicas pre y post jubilación tienen el objetivo de contribuir en esa transición, promoviendo bienestar, adaptación y mayor calidad de vida en el enfrentamiento de los cambios inherentes a esa etapa desarrollista. Meta: Este estudio de revisión integrada tuvo como objetivo descubrir el panorama de las intervenciones psicológicas utilizadas en los procesos de pre y post jubilación en Brasil. Método: La pregunta orientadora fue: ¿cuál es el perfil de las intervenciones psicológicas de la jubilación en términos de características, resultados y recomendaciones? Desde las bases de datos LILACS, SciELO, PePSIC y PsycINFO, se realizaron búsquedas en el período de 2002 a 2017. Resultados y Discusión: Se recuperaron diez artículos, siendo cinco empíricos y cinco teóricos. La mayoría tiene el objetivo de describir la importancia de los programas de preparación para la jubilación (PPA, en portugués). Las intervenciones afectaron más al público femenino y buscaron promover el bienestar explotando las pérdidas, ganancias y cambios que ocurrieron en esa etapa. Conclusión: Se recomienda que los psicólogos participen en estos programas, así como la evaluación longitudinal de las propuestas existentes, buscando su perfeccionamiento constante.

Palabras clave: jubilación, profesión, envejecimiento, psicoterapia

\section{Introdução}

A aposentadoria é um processo que pode ser compreendido por meio de uma perspectiva psicológica, visando a compreender e enfatizar os antecedentes comportamentais, subjetivos e as consequências para o indivíduo. Essa discussão, no entanto, não pode ser realizada sem a sua interface com outras áreas do conhecimento, a exemplo da economia e das ciências sociais. No cenário brasileiro, evidenciado no presente estudo, a discussão sobre a Reforma da Previdência no ano de 2019 tem trazido importantes elementos que podem e devem ser considerados quando pensamos em intervenções nessa área (Lavinas \& Cordilha, 2019). Com a possível elevação da idade com que as pessoas poderão se aposentar, a partir da presente Reforma, aspectos ligados ao ciclo vital ganham destaque. A aposentadoria revela-se um elemento complexo que interfere em diversos campos, passando pelas relações de trabalho, relações familiares, de saúde, de lazer, recuperando a necessidade de incluir nesse bojo as diferenças inter e intraindividuais, fatores biológicos, econômicos, culturais, sociais e psicológicos (Boehs, Medina, Bardagi, Luna, \& Silva, 2017; Löckenhoff, Terracciano, \& Costa Junior, 2009). Nesta fase, que, na maioria das vezes, pode coincidir com o enveIhecimento, muitos sentimentos ambivalentes e confusos podem aflorar. Segundo França e Murta (2014a), essa ambivalência pode ocasionar ansiedade, gerada por um mau planejamento desse processo, além de mudanças de humor, doenças psicossomáticas e medos, como o de perder o status de "estar na ativa".

O processo de preparação para a aposentadoria é crucial para a população (Arraché, 2012), haja vista as mudanças demográficas que vêm ocorrendo nas últimas décadas (Rafalski \& Andrade, 2017), bem como a emergência de mudanças econômicas e previdenciárias no contexto brasileiro (Colleti, Poletto, \& Scorsolini-Comin, 2020). Segundo Laidlaw e Pachana (2009), podemos notar o envelhecimento da população, ocasionado por um aumento da expectativa de vida. Apesar de uma parte da população conseguir conservar a sua qualidade de vida, uma parte mais significativa a perde consideravelmente, por conta de transtornos psicológicos e cognitivos, doenças crônicas e perda de funcionalidade, o que, em conjunto com as implicações financeiras e políticas, influenciam diretamente o processo de aposentadoria (Ferreira, 2016). 
Segundo França e Murta (2014a), o processo de transição para a aposentadoria, ao ser enfrentado sem preparação, pode gerar diversos impactos no contexto global do indivíduo, por representar o término de uma carreira. Durante o processo, é comum as pessoas se isolarem por conta da falta do contato com colegas e do ambiente de trabalho. Com a aposentadoria, muitos acabam por ter seu padrão de vida financeira diminuído e apresentam dificuldades de como utilizar o tempo ocioso (Arraché, 2012). Visando a tornar essa transição mais adaptativa para os indivíduos, existem os programas de preparação para a aposentadoria (PPA), que têm como finalidade auxiliar os trabalhadores a tomarem as decisões primordiais para que esses se adaptem à nova condição social de aposentados (Muniz, 1996). As organizações estão cada vez mais investindo nos PPAs, pois passaram a compreender que esses programas são excelentes ferramentas gerenciais, posto que estimula a atuação dos pré-aposentados nos grupos sociais (Gvozd, Haddad, Liberatti, \& Martins, 2015).

De acordo com Muniz (1996), há diversos modelos de PPA, sendo o mais utilizado o norte-americano, que consiste em cursos nos quais os participantes discutem as principais questões que angustiam as pessoas que estão prestes a se aposentar. Já o modelo espanhol inicia-se cinco anos antes da aposentadoria e visa a orientar quanto ao que acontecerá no futuro durante todo o processo. No Brasil, os PPAs geralmente visam a transmitir informações sobre a questão do envelhecimento, de serviços da comunidade que os indivíduos podem participar e de recursos socioculturais. Com isso, vemos que existem diversos modelos de PPAs, cada um com a sua particularidade, podendo diferir quanto ao número de encontros, aos objetivos, aos temas que são tratados, bem como em relação à duração das intervenções e às técnicas e perspectivas teóricas utilizadas.

Durante os PPAs, o trabalhador tem a possibilidade de ter contato com pessoas que estão passando por situações semelhantes às suas (Vuori, Toppinen-Tanner, \& Mutanen, 2012). Assim, é possível que haja troca de informações e adaptação às diferentes experiências. Nesse momento, os participantes têm a possibilidade de falar e refletir sobre o seu passado e futuro, o que faz com que o sujeito pense e comece a lidar com as mudanças que estão acontecendo ou que estão por vir (Arraché, 2012).

Segundo França (2016), as ações que ocorrem durante o processo de preparação podem ser longas ou breves, mas estão estruturadas para atingir as dimensões de saúde, atividade física, sexualidade, autopercepção, planejamento financeiro, alimentação saudável, legislação previdenciária, resiliência, projeto de vida, autonomia, ocupação, identidade, planos, organização do tempo livre e apoio social, tanto no nível familiar quanto com relação aos laços de amizade.

De acordo com Pazzim e Marin (2016), cerca de 23\% das organizações brasileiras oferecem PPAs. São diversos os fatores que contribuem para a escassez desses programas: a pouca consciência dos trabalhadores sobre os programas; a falta de profissionais especializados para realizarem as intervenções; as poucas publicações que avaliam tais programas e o baixo apoio por parte das empresas. Por conta desses fatores, por muitas vezes os trabalhadores que estão se aposentando não têm todo o suporte que deveriam ter nesse momento delicado. Tecnicamente, os PPAs deveriam sempre ocorrer, tanto no âmbito das instituições públicas quanto nas privadas, pois estão previstos no Estatuto do Idoso. Apesar dessa dificuldade destacada, nota-se um crescimento no número de PPAs disponibilizados pelas organizações (França \& Seidl, 2016). Além disso, na área da Psicologia, em sua interface com a saúde, 
existem poucos estudos envolvendo esses profissionais em transição de carreira, apesar de ser um assunto de suma importância (Pazzim \& Marin, 2016). Ainda assim, a Psicologia tem se revelado como uma das áreas mais atentas a esse processo, podendo estabelecer itinerários multidisciplinares para intervenções nesse cenário (Scorsolini-Comin et al., 2019).

A aposentadoria influencia o desenvolvimento social e econômico das pessoas e de todo um país, e por isso passou a ganhar maior visibilidade nos últimos anos (França \& Seidl, 2016). No bojo dessas considerações, é necessário averiguar se as intervenções realmente conseguiram alcançar seus objetivos: fazer com que os participantes manifestem emoções positivas ao avaliarem o processo de aposentadoria e passar por essa transição da maneira mais adaptativa. Frequentemente, essas emoções positivas podem se manifestar como felicidade, autoestima, otimismo, esperança, segurança a respeito do presente e do futuro, além de mudanças comportamentais (Bardagi \& Albanaes, 2015).

Nesse sentido, as intervenções psicológicas com essa população têm se tornado cada vez mais frequentes, tanto em termos de PPA como para as pessoas que já se aposentaram e estão se adaptando a essa nova fase (Scorsolini-Comin, 2015; Scorsolini-Comin et al., 2019). A partir dessa contextualização, o objetivo deste estudo é conhecer o panorama das intervenções psicológicas utilizadas nos processos de pré e pós-aposentadoria no contexto brasileiro. Para atingir esse objetivo, o estudo buscou: (a) conhecer as principais questões emergentes nas intervenções nacionais realizadas com pessoas em preparação para a aposentadoria; (b) discutir o papel do profissional de Psicologia nesses processos; (c) conhecer as características desses programas. Esses aspectos tornam-se importantes, haja vista o interesse cada vez mais acentuado da Psicologia nesse contexto de intervenção (Scorsolini-Comin et al., 2019) e as recentes mudanças previdenciárias no país, que devem ser acompanhadas de discussões também em termos de saúde mental do trabalhador, considerando-se a ampliação do tempo de contribuição e da idade para se aposentar na maioria dos segmentos profissionais (Lavinas \& Cordilha, 2019). Assim, conhecer a literatura consolidada acerca do tema pode ser útil na discussão das intervenções que serão trazidas à baila futuramente, em função, também, dessas mudanças importantes, o que deve ser representado na literatura científica dos próximos anos.

\section{Método}

\section{Tipo de Estudo}

Trata-se de uma revisão integrativa da literatura científica que, segundo Mendes, Silveira e Galvão (2008), permite a incorporação das evidências científicas na prática, por incluir a análise de pesquisas relevantes que dão suporte para a tomada de decisão. Ainda de acordo com essas autoras, a revisão deve ser realizada em seis etapas: (a) estabelecimento da questão norteadora; (b) delimitação dos critérios de inclusão e de exclusão; (c) determinação de quais serão as informações que farão parte ou não do seu estudo; (d) análise dos dados; (e) discussão e interpretação dos resultados; (f) elaboração do relatório final. A questão norteadora foi: qual o perfil das intervenções psicológicas realizadas no contexto da aposentadoria em termos de características, resultados e recomendações? 


\section{Bases consultadas e descritores}

Foram consultadas as bases de dados/bibliotecas PePSIC, LILACS, SciELO e PsycINFO, fazendo o uso de combinações com 16 unitermos em dois idiomas diferentes (português e inglês). As combinações empregadasforam, em português: Psicoterapia AND Aposentadoria; Aposentad\# AND psic\#; Intervenção AND psicológica AND aposentado; Aposentado AND Carreira; Carreira AND Envelhecimento; Psicoterapia AND Idoso AND Aposentadoria; Velhice AND Aposentadoria; Idosos AND Aposentadoria; Preparação AND Pré-Aposentadoria; Orientação AND Aposentadoria; Programa AND Aposentadoria. Esses unitermos foram previamente consultados na Terminologia em Psicologia disponível na BVS-Psi.

\section{Critérios de inclusão e de exclusão}

Foram incluídos os seguintes estudos: (1) artigos indexados; (2) artigos redigidos em português e inglês; (3) publicados no período de janeiro de 2002 a abril de 2017; (4) com temática pertinente ao objetivo da revisão, isto é, que tratavam de intervenções psicológicas no processo de aposentadoria; (5) que respondessem à pergunta norteadora; (6) que descrevessem intervenções psicológicas nesse contexto ou que trouxessem direcionamentos ou recomendações para a realização de intervenções psicológicas em aposentadoria; (7) que abordassem as intervenções em termos de características, planejamento, execução e/ou avaliação de programas e intervenções voltados a aposentados ou pessoas em processo de preparação para a aposentadoria; (8) que abordassem intervenções para a realidade brasileira. Não houve restrição em relação ao tipo de estudo - se empírico ou teórico, haja vista que um levantamento prévio localizou poucas referências. Assim, optou-se por não fazer tal restrição apenas aos estudos empíricos, o que poderia reduzir ainda mais o espectro de considerações sobre o tema.

Foram excluídos os seguintes trabalhos: (1) livros, capítulos de livro, resenhas, cartas, notícias, dissertações e teses; (2) artigos que se distanciassem do tema em questão; (3) artigos sobre doenças provenientes do envelhecimento; (4) artigos que não apresentassem intervenções psicológicas ou como estas se davam; (5) artigos em outros idiomas que não o português e inglês; (6) publicados antes de 2002 e após abril de 2017; (7) artigos que apresentassem ou discutissem intervenções realizadas exclusivamente em outros países que não o Brasil.

\section{Procedimento}

Coleta de dados. Primeiramente, foram realizadas buscas sem filtros, com a posterior aplicação dos filtros descritos nos critérios de inclusão e exclusão. Após as buscas, ocorreu a exclusão dos artigos repetidos. Os artigos foram selecionados pela leitura dos títulos e resumos e, posteriormente, a partir da leitura dos resumos. Ao final desse processo, os artigos foram lidos na íntegra e um novo filtro foi aplicado, permanecendo no corpus apenas os estudos que respondessem à questão norteadora. Esse procedimento foi realizado por duas juízas independentes, ambas com experiência em revisões de literatura e na temática do estudo, sendo que as possíveis discrepâncias foram solucionadas por um terceiro juiz. Desse modo, permaneceram no corpus apenas as produções que passaram por essa análise. 
Análise dos dados. Os artigos recuperados ao final desse processo compuseram o corpus analítico e foram interpretados a partir da literatura sobre as intervenções psicológicas neste contexto. O processo analítico consistiu em uma breve explanação sobre cada artigo, seguido de sua leitura de modo integrado, apontando semelhanças e diferenças entre esses estudos. Os artigos foram classificados em termos de: autores, instituição de origem dos autores, periódico, ano de publicação, objetivos, amostra, resultados e conclusões. Após essa classificação, foram construídas categorias analíticas para organizar os achados e responder, ao final, à pergunta norteadora.

\section{Resultados}

O procedimento de seleção, análise e composição da amostra está representado na Figura 1, e as informações relevantes para caracterização do corpus de análise estão compiladas na Tabela 1. A maior parte dos artigos foi encontrada na base de dados LILACS, sendo também a base de onde foi recuperada a maior parte dos artigos utilizados nesta revisão.

Figura 1. Fluxograma com os procedimentos de seleção dos artigos

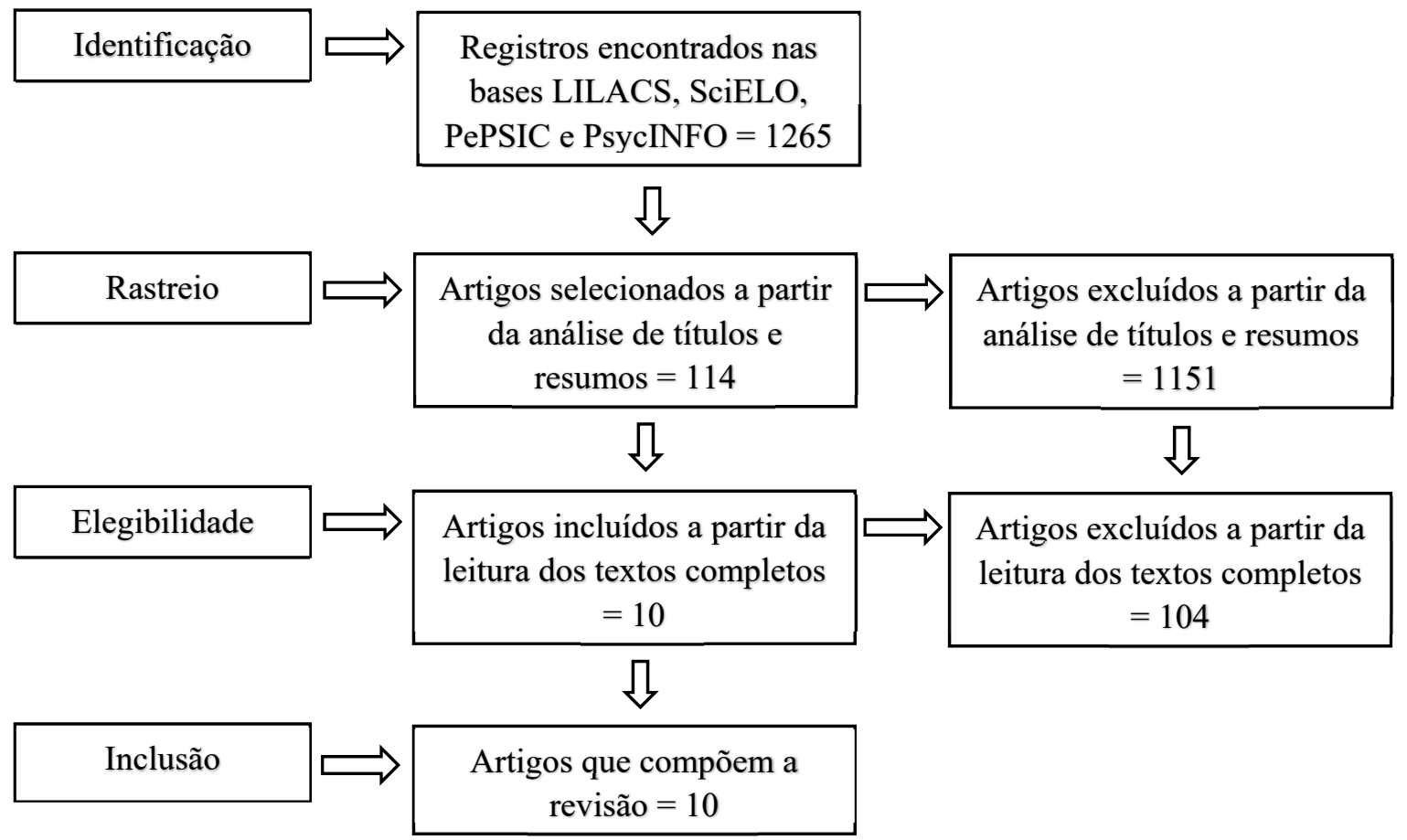

Após aplicar os critérios de inclusão e de exclusão, dos 1.265 artigos encontrados, 114 foram selecionados a partir da leitura dos resumos, sendo que havia diversos artigos repetidos nas diferentes bases de dados. Após a leitura dos textos na íntegra, foram recuperados 10 artigos. A Tabela 1 compila algumas informações relevantes para caracterização do corpus de análise. Houve equilíbrio entre os estudos de caráter empírico (Soares, Luna, \& Lima, 2010; França, Menezes, \& Siqueira, 2012; França, Murta, Negreiros, Padralho, \& Carvalhedo, 2013; Murta et al., 2014; Figueira, Haddad, Gvozd, \& Pissinati, 2017) e de caráter teórico (Rodrigues, Ayabe, Lunardelli, \& Canêo, 2005; Costa \& Soares, 2009; França \& Soares, 2009; Zanelli, 2012; França \& Murta, 2014b). 
Sumarizando os achados, as intervenções recuperadas têm como característica predominante o enfoque grupal na modalidade breve, desenvolvidas em pequenos grupos, com a participação maciça de mulheres. O acompanhamento dessas intervenções revela a queda de participação ao longo dos encontros e no seguimento. A necessidade de apoio psicológico nessa fase é mencionada de modo expressivo na literatura,

A partir da análise desse corpo de literatura, pode-se afirmar que os estudos empíricos se propõem a descrever experiências exitosas, ainda que exista dificuldade em desenvolver e empregar protocolos que permitam uma análise segura em relação aos resultados das intervenções realizadas. Isso equivale a considerar que os programas recuperados na literatura, embora sejam quase sempre submetidos a uma avaliação, ainda são eminentemente descritivos, subsidiando reflexões para próximas intervenções, mas não gerando evidências que possam ser apresentadas com segurança, a fim de validar algum protocolo, por exemplo. Essa dificuldade, embora seja assinalada nesse campo dos estudos da aposentadoria, também se mostra em outras áreas da Psicologia. As intervenções de base clínica, por exemplo (Scorsolini-Comin et al., 2019), têm especificidades em sua mensuração, bem como de avaliação longitudinal, o que pode interferir na opção por perfis de estudos mais descritivos. Essas descrições, no entanto, são úteis para o delineamento de projetos na área e podem convidar os profissionais da área a diferentes reflexões, sobretudo em termos da organização dos programas, tipos de intervenções, duração e público-alvo.

Tabela 1

Classificação dos Estudos Recuperados ( $N=10)$

\begin{tabular}{|c|c|c|}
\hline Categorias & $\begin{array}{l}\text { Características } \\
\text { e frequências absolutas }\end{array}$ & Exemplos na amostra \\
\hline $\begin{array}{l}\text { Instituição de origem } \\
\text { do primeiro autor }\end{array}$ & $\begin{array}{l}\operatorname{UFSC}(n=2) \\
\operatorname{UnB}(n=2)\end{array}$ & $\begin{array}{l}\text { Zanelli (2012) } \\
\text { França e Murta (2014b) }\end{array}$ \\
\hline Tipos de estudo & $\begin{array}{l}\text { Empírico }(n=5) \\
\text { Teórico }(n=5)\end{array}$ & $\begin{array}{l}\text { Figueira et al. (2017) } \\
\text { Costa e Soares (2009) }\end{array}$ \\
\hline Publicação & $\begin{array}{l}2012(n=3) \\
2014(n=2)\end{array}$ & $\begin{array}{l}\text { França et al. (2012) } \\
\text { França e Murta (2014b) }\end{array}$ \\
\hline Objetivos & $\begin{array}{l}\text { Investigar o panorama dos trabalhadores } \\
\text { e propor PPAs visando a reflexões que } \\
\text { podem prevenir possíveis problemas } \\
\text { ocasionados por esse período. }\end{array}$ & $\begin{array}{l}\text { Rodrigues et al. (2005) } \\
\text { Soares et al. (2010) }\end{array}$ \\
\hline Resultados & $\begin{array}{l}\text { As intervenções e o planejamento da } \\
\text { aposentadoria conseguem trazer grande } \\
\text { satisfação. }\end{array}$ & $\begin{array}{l}\text { França et al. (2013) } \\
\text { Murta et al. (2014) }\end{array}$ \\
\hline Conclusões & $\begin{array}{l}\text { Devem ser realizados mais estudos } \\
\text { para aprimorar as intervenções que são } \\
\text { realizadas com tal população. }\end{array}$ & $\begin{array}{l}\text { França e Soares (2009) } \\
\text { França e Murta (2014a; 2014b) }\end{array}$ \\
\hline
\end{tabular}

\section{Discussão}

A partir dos objetivos propostos na revisão, o corpus será discutido a partir dos seguintes tópicos: (a) questões emergentes no processo de preparação para a aposentadoria; (b) o papel do psicólogo nas intervenções no contexto da aposentadoria; e (c) como se dão as intervenções nesse contexto. 


\section{Questões emergentes no processo de preparação para a aposentadoria}

A Política Nacional do Idoso, com a Lei n. 8.842, de 4 de janeiro de 1994, propunha que as empresas dos setores públicos e privado criassem e mantivessem as iniciativas dos PPAs, sendo que esses deveriam ocorrer com no mínimo dois anos antes da aposentadoria dos indivíduos, visto que, nesse período, os profissionais já começam a pensar nessa realidade (Rodrigues et al., 2005). Além disso, em 2003, foi sancionada a Lei n. 10.741, do Estatuto do Idoso no Brasil. Com ela, fica prevista a implantação de PPAs e outras ações que visam à promoção e qualidade de vida dos idosos. Dessa maneira, o poder público acredita que está estimulando o desenvolvimento de novos PPAs e o aumento do público que os programas existentes abrangem (Costa \& Soares, 2009; França et al., 2013). Apesar de as duas leis preverem a implantação nas empresas e nos órgãos governamentais e não governamentais, muitas vezes elas não são cumpridas ou o programa não é efetivo, visto que os profissionais não conhecem a metodologia do PPA ou não compreendem a importância de uma reflexão acerca da aposentadoria (Rodrigues et al., 2005).

A aposentadoria é um momento muito desejado e esperado pelos trabalhadores. Grande parte dos pré-aposentados e dos aposentados desejam realizar as mais diversas atividades, de desenvolvimento pessoal até de lazer, aprender uma nova língua, viajar, dedicar-se mais à família e aprimorar os relacionamentos (França \& Soares, 2009; Zanelli, 2012). É importante reafirmar que a transição do trabalho para a aposentadoria tem início antes de o trabalhador encerrar a sua atividade laboral, e esse período de transição se estende até após a aposentadoria ser formalizada (França \& Soares, 2009).

França e Soares (2009) e Murta et al. (2014) apontam que a aposentadoria proporciona ganhos e perdas, sendo os ganhos reforçados, ao passo que as perdas são utilizadas como aprendizado, fazendo com que seja possível a criação de estratégias que facilitam o enfrentamento de possíveis adversidades. Além de toda a transição, este é um período em que ocorrem diversas mudanças: há perdas na saúde física, por conta do avanço da idade (França \& Murta, 2014b; Murta et al., 2014), perda da saúde mental e perdas financeiras, visto que, frequentemente, há uma diminuição significativa da renda, sendo o valor da aposentadoria inferior ao salário. Ocorrem também as perdas dos benefícios, como plano de saúde (Costa \& Soares, 2009; França \& Murta, 2014b; Murta et al., 2014). Já segundo França e Soares (2009), os principais ganhos durante a aposentadoria são: a liberdade, o tempo disponível e a possibilidade de um novo começo.

Segundo França e Murta (2014b), a perda salarial causa um grande impacto no relacionamento familiar, modificando a qualidade de vida da família. Desta maneira, percebemos que realmente há diversos fatores que dificultam uma boa transição para a aposentadoria, como já apresentado, além dos cenários político, cultural, socioeconômico e familiar (Murta et al., 2014).

O estresse é uma doença que recebeu destaque em diversos estudos. Com o desenvolvimento de intervenções, é possível reduzir os efeitos negativos do estresse, possibilitando a promoção da saúde (Vuori et al., 2012). Zanelli (2012) traz a possibilidade de ser realizada uma adaptação e redução do estresse, fazendo com que diversos fatores desencadeadores, como a questão financeira, a família e as condições de saúde, possam ser repensadas e aprimoradas. 
Uma das questões mais demonstradas nos estudos foi a perda financeira. França et al. (2012) apresentam a dicotomia que há na sociedade, demonstrando que há aposentados que recebem apenas o suficiente para sobreviver, enquanto outros são privilegiados, visto que possuem recursos financeiros que permitem o desfrute de uma vida social intensa. Antes de se aposentarem, os trabalhadores passam a refletir e presumem que, na aposentadoria, haverá uma perda financeira (Zanelli, 2012). Para alguns trabalhadores, essa perda impossibilita que eles realizem atividades de lazer e de desenvolvimento que são importantes nesse período. Para evitar esses pensamentos, faz-se necessário o planejamento financeiro em médio e longo prazo. Desta forma, França e Soares (2009) ressaltam a importância de uma educação ao longo da vida, fazendo com que esse desafio, entre outros, seja superado.

No período da transição, é comum os sentimentos de solidão, inutilidade (França \& Murta, 2014b), perda de lugar no meio produtivo (Costa \& Soares, 2009), mudança no equilíbrio psíquico, angústia (Rodrigues et al., 2005) e mudança na identidade do sujeito (Costa \& Soares, 2009; Rodrigues et al., 2005). Assim, as intervenções no contexto da preparação para aposentadoria emergem como uma forma de planejamento e prevenção (Rodrigues et al., 2005). A preparação junto da gestão de carreira ocasiona impactos em longo prazo e afeta positivamente a vida do indivíduo, principalmente a saúde mental do trabalhador.

França e Soares (2009), Rodrigues et al. (2005) e Zanelli (2012) elencaram a importância do bem-estar, da saúde física e emocional, da família e da organização para que esse período de transição do trabalho para a aposentadoria seja vivido de maneira saudável. Assim, todos os meios em que esse sujeito está inserido devem buscar o bem-estar geral, abrangendo os ambientes psicológico, tecnológico, político, sociológico e econômico.

Já Zanelli (2012) e Figueira et al. (2017) destacam a importância das relações familiares durante a tomada de decisão de se aposentar. Uma boa relação e fortes conexões familiares, em especial com o cônjuge, favorecem um bom ajuste no processo de transição para a aposentadoria. Casais em que os cônjuges tiveram uma boa transição tendem a usufruir de uma boa satisfação conjugal (Zanelli, 2012).

A partir dos aspectos aqui recuperados, pode-se sumarizar que as principais questões que emergem nas intervenções de preparação para a aposentadoria referem-se à perda salarial, ao adoecimento mental e às relações psicossociais, sobretudo as familiares. Essas parecem ser as áreas que mobilizam os trabalhadores, haja vista que a aposentadoria acaba impondo, comumente, a redução dos proventos e também uma maior aproximação com as questões familiares e de convivência. Esses aspectos, associados à instabilidade desse período e às mudanças também em relação ao desenvolvimento, como a proximidade da velhice, acabam despertando sentimentos que demandam um manejo específico. Agravamentos de saúde mental, como a questão do estresse, foram relatados na literatura.

Desse modo, o apoio psicológico nessa transição e nas diversas situações enfrentadas na fase da aposentadoria tem se mostrado importante (Costa \& Soares, 2009). Assim, deve-se estimular o engajamento dos trabalhadores nas intervenções oferecidas, haja vista que ainda são poucos os profissionais que realizam e se interessam por elas (França \& Soares, 2009). No eixo a seguir, abordaremos o lado dos profissionais que conduzem e executam esses programas. 


\section{O papel do psicólogo nas intervenções no contexto da aposentadoria}

Como mencionado, durante esse período de transição de carreira, a população pré-aposentadoria está sujeita a diversas vulnerabilidades. Porém, com uma preparação para um enfrentamento adequado, há a possibilidade de os aposentados experienciarem esse período de uma maneira bem-sucedida (Murta et al., 2014). A preparação dessa transição, juntamente de um psicólogo, acaba por estimular uma melhor adaptação, fazendo com que o indivíduo possa progredir e enfrentar as dificuldades mais estressantes.

Segundo Rodrigues et al. (2005) e França e Murta (2014a), no Brasil, a atuação dos psicólogos organizacionais é caracterizada, predominantemente, pela reprodução de objetivos técnicos. Isso faz com que haja uma grande dificuldade de se realizar intervenções voltadas à preparação para a aposentadoria dentro do contexto organizacional. Na área de gestão de pessoas, o psicólogo tem diversas atribuições (Rodrigues et al., 2005), sendo uma delas a promoção de qualidade de vida dos trabalhadores. Contudo, quando se trata de intervenções psicológicas no processo de preparação para a aposentadoria, não há muitos estudos disponíveis na literatura que versem a respeito dessa temática (Costa \& Soares, 2009; Soares et al., 2010). Entretanto, já é sabido que, durante o PPA, a participação do psicólogo é de suma importância para os trabalhadores que estão passando por essa transição (Costa \& Soares, 2009).

A atuação dos psicólogos no processo de aposentadoria se faz necessária, pois possibilita que o sujeito se valorize neste novo momento da sua vida, fazendo com que os participantes vejam outras alternativas para se ter um projeto de vida saudável. Com a participação do psicólogo, os participantes têm a possibilidade de ter uma nova visão de vida saudável, uma vez que essa não se refere unicamente à saúde física, mas também à saúde mental (Costa \& Soares, 2009). Assim, os psicólogos organizacionais podem criar e desenvolver políticas de gestão de pessoas que façam com que a transição seja vivida de forma gradual e, portanto, não haja uma mudança abrupta no cotidiano de trabalho, diminuindo as chances de a transição ser vivida de forma negativa.

Segundo Soares et al. (2010), o PPA "A Arte de Aposentar-se" foi desenvolvido por psicólogos, proporcionando um incentivo para que cada indivíduo construísse e, assim, realizasse seu processo de aposentadoria de forma única, possibilitando a autonomia de cada um diante dessa nova perspectiva. Outro programa foi descrito por Scorsolini-Comin (2015), com servidores públicos federais atendidos por meio da modalidade do aconselhamento psicológico. Esses atendimentos psicoterápicos eram oferecidos como parte do PPA da instituição onde esses servidores federais trabalhavam, sendo as intervenções apontadas pelos participantes como importantes espaços nesse período de transição.

Com exceção da modalidade psicoterápica descrita no estudo de Scorsolini-Comin (2015), todas as demais intervenções podem e devem ser conduzidas por profissionais de diferentes áreas, haja vista que a aposentadoria apresenta interfaces com questões específicas do Direito, apenas para citar um exemplo. Ainda de acordo com a literatura consultada, as intervenções existentes tradicionalmente partem de uma ação mais integrada, considerando-se que a aposentadoria pode coincidir com desafios desenvolvimentais da transição da vida adulta para o envelhecimento. Assim, preparar-se para a aposentadoria também é preparar-se para uma outra etapa desenvolvimental, na maioria dos casos. 
Os psicólogos integrados a uma equipe multiprofissional ampliam a possibilidade de elaborar de forma mais especifica as atividades e objetivos para cada grupo de PPA (Rodrigues et al., 2005). Desta forma, é possível recuperar a qualidade de vida dos trabalhadores e prevenir as eventuais doenças que podem ser ocasionadas por esse processo estressante (França \& Murta, 2014b). Portanto, a literatura recuperada na presente revisão aponta que o apoio psicológico nessa fase tem sido fundamental nessa transição e adaptação ao novo período. Podemos concluir que, embora as ações multidisciplinares e mesmo interprofissionais existam e sejam recomendadas, a atuação do profissional de Psicologia nesse processo é premente na maior parte das intervenções recuperadas. Essa consideração deve ser também associada ao fato de que a Psicologia tem se mostrado uma das áreas que mais investigam essa transição para a aposentadoria.

\section{Como se dão as intervenções no contexto da aposentadoria}

As intervenções nesse contexto da aposentadoria podem ser realizadas de diversas formas. A literatura aponta a estrutura grupal como a mais recorrente (França et al., 2012; Murta et al., 2014; França et al., 2013; Soares et al., 2010), com duração que varia de sete meses a apenas três encontros (Soares et al., 2010), o que caracteriza essas últimas como intervenções breves (França et al., 2012; França et al., 2013; Soares et al., 2010).

As intervenções realizadas no Brasil geralmente são breves, como demonstrado nos estudos que compõem essa revisão, com média de: seis encontros (França et al., 2012); oito módulos (Murta et al., 2014); quatro intervenções e três encontros para realização de um monitoramento (França et al., 2013); cinco encontros, realizados uma vez por mês e que duravam aproximadamente duas horas cada (Figueira et al., 2017); e três encontros que totalizavam 24 horas (Soares et al., 2010). Outras são realizadas ao longo de todo o ano, com um encontro mensal de duas horas de duração, por exemplo (Scorsolini-Comin, 2015). As intervenções, mesmo sendo breves, mostraram-se com um grande potencial. Contudo, estas ainda não seguem as exigências prescritas pelas leis brasileiras. No geral, o período de transição para a aposentadoria dura cerca de quatro a seis anos, sendo dois ou três antes da aposentadoria e dois ou mais anos após o afastamento da ocupação, e é esse período que os PPAs deveriam abranger. Considerando essas informações, temos que os PPAs poderiam ser intervenções de longa duração, o que não foi observado em nenhum dos estudos reunidos neste artigo.

Observou-se que, no país, são poucos os trabalhadores que conhecem, interessam-se e participam dos PPAs. No estudo realizado sobre o PPA de Soares et al. (2010), dos 20 inscritos, somente 15 compareceram ao programa, sendo cinco já aposentados; outros cinco que ainda trabalhavam, mas que já poderiam ter se aposentado; e outros cinco que estavam prestes a se apresentar. É importante ressaltar que esses três grupos são o público-alvo do PPA, contudo é possível observar que poucos estudos conseguiram atingir todo esse público-alvo. Dados semelhantes foram apresentados na intervenção de Scorsolini-Comin (2015).

Nesse sentido, temos que a divulgação dos PPAs é de suma importância para que o programa ganhe visibilidade. Murta et al. (2014) investiram em uma maior divulgação de seu programa, contando com meios eletrônicos e a abordagem das chefias das organizações, a 
fim de sensibilizá-las para a participação das equipes nessas intervenções. Com uma maior divulgação e apresentação do programa nas empresas, e instalação de novas parcerias, é possível atrair novos participantes para o PPA.

Os estudos de Soares et al. (2010), França et al. (2013), Murta et al. (2014) e Figueira et al. (2017) observaram que há quedas de participação, desde o ato da inscrição até os primeiros encontros e, também, nos monitoramentos que ocorrem posteriormente à intervenção. No estudo de Soares et al. (2010), dos 20 inscritos, somente 15 compareceram aos encontros, assim como no estudo de Figueira et al. (2017), que, dos 20 inscritos, houve a participação de 16 sujeitos. Já no estudo de França et al. (2013) a queda de participantes foi intensificada nos monitoramentos, assim como no estudo de Murta et al. (2014). Assim, foi possível observar que não há assiduidade total por parte dos participantes, o que acaba por desestimular esses programas. Mais do que apontar essas desistências, faz-se importante que as intervenções incluam pesquisas que possam compreender as motivações para essas faltas, aperfeiçoando os convites e a atração desse público, promovendo, de fato, um programa que possa servir a esses participantes e prepará-los para essa transição de carreira.

Percebeu-se que as mulheres são as principais participantes dos PPAs. Nos estudos de França et al. (2013) e de Figueira et al. (2017), observou-se que cerca de 80\% dos participantes dos programas de preparação eram do sexo feminino. De acordo com França e Murta (2014b), as mulheres conseguem se adaptar de forma mais positiva à aposentadoria do que os homens, e isso se deve ao fato de elas conseguirem atuar em diversos papéis, desde filhas até esposas. Além disso, as mulheres frequentemente dedicam-se a outras atividades após o afastamento do trabalho, o que pode ser considerado um fator que previne e antecipa a adaptação na aposentadoria.

Em termos das intervenções e seus delineamentos, no estudo de Murta et al. (2014) era solicitado que os participantes realizassem "tarefas de casa". Nessas, os membros escolhiam algo para realizar durante a semana. Contudo, essa ação deveria ser relacionada com um dos temas que já haviam sido abordados nos encontros. França et al. (2012) e Murta et al. (2014) realizaram entrevistas semiestruturadas com os participantes, em que foi possível observar por quais temas os sujeitos mais se interessavam e sentiam necessidade de falar, para que assim ocorressem os grupos focais. No estudo de França et al. (2012), foram abordados os seguintes temas: relacionamento social, investimentos e novas oportunidades de trabalho, novo começo, saúde e lazer, relacionamentos familiares e as influências do planejamento para uma aposentadoria com bem-estar. Já o estudo de Murta et al. (2014) visou a enfatizar as caracterizas da transição para a aposentadoria, as estratégias que podem ser utilizadas na aposentadoria, as vivências dessa população e o que poderia ser feito para que os trabalhadores se sentissem mais preparados para essa transição.

Apesar de cada modelo fazer uso de uma técnica diferente, é de extrema importância, para a realização de uma boa intervenção, que haja uma combinação de entrevistas com a aplicação de testes e escalas psicológicas, pois assim é possível observar as necessidades de cada participante e realizar intervenções adequadas para cada indivíduo. No levantamento proposto, não foram encontrados PPAs realizados de forma individual, o que nos remete à importância de novos estudos acerca deste tema, que ainda é pouco difundido. No entanto, em estudo mais recente (Scorsolini-Comin et al., 2019), foi encontrada a descrição de uma proposta psicoterápica individual para pessoas em transição para a aposentadoria. Essas 
intervenções podem ou não estar associadas a intervenções grupais de PPAs, ou seja, podem ser complementares aos PPAs ou se constituírem como intervenções exclusivas.

Nos estudos de França et al. (2013) e Murta et al. (2014), foram observados pontos de melhoria a partir das avaliações de seus participantes. Entre os aspectos relatados, encontramos a breve duração das intervenções, seguida da importância de palestras com temas mais abrangentes, como atividades físicas e independência. Esses mesmos autores realizaram monitoramentos após as intervenções, visando a observar como essas afetaram e modificaram o cotidiano dos participantes, destacando a importância de se incorporar os dados desse follow-up para o aprimoramento constante dos programas. Sistematizar essas avaliações e acompanhar os egressos desses programas no longo prazo parecem ser desafios a essas intervenções, o que deve ser associado a sólidos investimentos em pesquisa nesse campo. As recentes mudanças previdenciárias no cenário brasileiro podem ser motivadoras no sentido de incrementar essas investigações e permitir a produção de evidências mais sólidas para futuras práticas.

\section{Considerações Finais}

Apesar de os estudos recuperados na presente revisão apontarem a satisfação dos sujeitos que participaram das intervenções, foram destacados alguns pontos de melhoria para intervenções futuras. Foi possível averiguar uma queda significativa de cerca de $20 \%$ na participação durante as intervenções analisadas. Esse é um dado relevante, já que a oferta dos PPAs ainda é escassa. Essa queda de participação pode desestimular ainda mais as organizações e os participantes que realizam e frequentam tais programas (Murta et al., 2014). No entanto, a partir de um cenário de mudanças no Brasil, sobretudo a partir dos anos de 2018 e 2019, o que ainda será acolhido pela pesquisa científica, hipotetiza-se que essas intervenções ganhem cada vez mais relevância. Em que pese o provável aumento da idade em que as pessoas se aposentarão, tais intervenções podem receber cada vez mais um público composto por idosos, apresentando mais demandas em relação ao envelhecimento, de modo concomitante.

Os estudos apresentaram como principais características o desenvolvimento de temas abrangentes que são associados ao processo de aposentadoria. Pelas descrições dos processos e das avaliações disponíveis, houve sinalizações no sentido da efetividade das intervenções breves. Esses estudos apontaram também para a melhoria do bem-estar da população atendida, que é resultado de as intervenções terem focado nos ganhos, nas perdas e nas mudanças que ocorrem nesse período de transição.

Averiguou-se que os estudos proporcionam grandes benefícios para aqueles que deles participaram. Sugere-se a participação de psicólogos nas intervenções nesse contexto, além de mais estudos a respeito da temática, visando a descrever diferentes propostas, bem como a avaliação focada na preparação e no acompanhamento desse público ao longo dessa transição. Aliar descrição de modelos e experiências com a avaliação destes parece ser um desafio nesse campo, como evidenciado na presente revisão. Notaram-se poucos modelos existentes, bem como escassez de direcionamentos para a construção de programas a partir de diferentes realidades organizacionais, o que pode ser conduzido não apenas a partir da divulgação de relatos, mas também de reflexões sobre modelos e as potencialidades deles. 
Por fim, há de se destacar que o cenário previdenciário brasileiro encontra-se em processo de redefinição em função da Reforma Previdenciária debatida no Congresso Nacional desde o ano de 2016 (Lavinas \& Cordilha, 2019). Há de se considerar que esse período de intensos debates sobre a aposentadoria pode interferir nesses programas, o que pode ocorrer também após a definição dessa reforma e de suas repercussões concretas para o mundo do trabalho e para o universo da transição para a aposentadoria. Assim, essas decisões macropolíticas e macroeconômicas podem interferir no modo como esses programas vão se estruturar, em termos das dúvidas que poderão emergir ao longo das intervenções e até mesmo no perfil das pessoas que participam dessas propostas. Assim, em um cenário de transição e instabilidade que afeta diretamente a aposentadoria, bem como o direito e o desejo de aposentar-se, deve-se destacar que os dados aqui presentes podem ser revistos em função desses ajustes e, mais do que isso, dos estudos que serão realizados a partir desse período na tentativa de compreender essas repercussões que têm sido acenadas. Acompanhar a evolução desse cenário é fundamental.

Em termos das limitações da presente revisão, recomenda-se o acesso a materiais como dissertações e teses como forma de entrar em contato com produções que, porventura, não tenham sido publicadas em periódicos. Apesar de essa estratégia divergir de um estudo de revisão integrativa, abre-se a possibilidade de localizar mais estudos que, de fato, apresentem outros programas e possíveis alternativas e encaminhamentos no atendimento a esse público diante da aposentadoria, ampliando o rol de conhecimento acerca do tema e fortalecendo a proposição de novas intervenções e a produção de mais conhecimentos no campo da aposentadoria.

Também, o acesso a PPAs a partir de sites de grandes empresas públicas e privadas pode ampliar o repertório de intervenções existentes, haja vista que nem todo PPA, necessariamente, é alvo de investigação científica. Ainda que alguns programas não estejam alicerçados em pesquisas científicas, podem trazer elementos importantes para esse campo do conhecimento. Ampliar as evidências científicas, desse modo, é uma necessidade nesse cenário, sobretudo considerando a pouca diversidade de intervenções registradas no país e a concentração dessa produção em poucos núcleos de pesquisa.

\section{Referências}

Arraché, E. M. (2012). Qualidade de vida e expectativas com a pré-aposentadoria em servidores da UFRGS (Trabalho de Conclusão de Curso, Especialização em Qualidade de Vida e Envelhecimento, Universidade Federal do Rio Grande do Sul, Porto Alegre, Brasil).

Bardagi, M. P., \& Albanaes, P. (2015). Avaliação de intervenções vocacionais no Brasil: uma revisão da literatura. Revista Brasileira de Orientação Profissional, 16(2), 123-135.

Boehs, S. T. M., Medina, P. F., Bardagi, M. P., Luna, I. N., \& Silva, N. (2017). Revisão da literatura latino-americana sobre aposentadoria e trabalho: perspectivas psicológicas. Revista Psicologia Organizações e Trabalho, 17(1), 54-61.

Colleti, M., Poletto, M., \& Scorsolini-Comin, F. (2020). Como se preparar para a aposentadoria? Apontamentos para uma intervenção clínica inspirada na Psicologia Positiva. In C. H. Giacomoni, \& F. Scorsolini-Comin (Orgs.), Temas Especiais em Psicologia Positiva (pp. 137150). Petrópolis, RJ: Vozes. 
Costa, A. B., \& Soares, D. H. P. (2009). Orientação psicológica para a aposentadoria. Revista Psicologia Organizações e Trabalho, 9(2), 97-108.

Ferreira, H. G. (2016). Envelhecimento bem-sucedido: estamos preparados? Revista Ciências em Saúde, 6(4), 1-3.

Figueira, D. A. M., Haddad, M. C. L., Gvozd, R., \& Pissinati, P. S. C. (2017). A tomada de decisão da aposentadoria influenciada pelas relações familiares e laborais. Revista Brasileira de Geriatria e Gerontologia, 20(2), 207-215.

França, C. L. (2016). Efeito de programas de preparação para aposentadoria: um estudo experimental (Tese de Doutorado em Psicologia Clínica e Cultura, Universidade de Brasília, Brasília-DF, Brasil).

França, C. L., \& Murta, S. G. (2014a). Prevenção e promoção da saúde mental no envelhecimento: conceitos e intervenções. Psicologia: Ciência e Profissão, 34(2), 318-329.

França, C. L., \& Murta, S. G. (2014b). Fatores de risco e de proteção na adaptação à aposentadoria. Psicologia Argumento, 32(76), 33-43.

França, C. L., Murta, S. G., Negreiros, J. L., Pedralho, M., \& Carvalhedo, R. (2013). Intervenção Breve na Preparação para Aposentadoria. Revista Brasileira de Orientação Profissional, 14(1), 99-110.

França, L. H. F. P., \& Seidl, J. (2016). Resenha: Manual da Oxford sobre aposentadoria. Revista Psicologia Organizações e Trabalho, 16(3), 308-310.

França, L. H. F. P., \& Soares, D. H. P. (2009). Preparação para a aposentadoria como parte da educação ao longo da vida. Psicologia: Ciência e Profissão, 29(4), 738-751.

França, L. H. F. P., Menezes, G. S., \& Siqueira, A. R. (2012). Planejamento para aposentadoria: a visão dos garis. Revista Brasileira de Geriatria e Gerontologia, 15(4), 733-745.

Gvozd, R., Haddad, M. C. L., Liberatti, V. M., \& Martins, J. T. (2015). Implantação de um programa de preparação para aposentadoria em instituição universitária pública. Revista de Enfermagem UFPE On line, 9(2), 994-1000.

Laidlaw, K., \& Pachana, N. A. (2009). Aging, mental health, and demographic change: Challenges for psychotherapists. Professional Psychology: Research and Practice, 40(6), 601-608.

Lavinas, L., \& Cordilha, A. C. (2019). Reforma da Previdência: qualificando o debate brasileiro à luz de experiências internacionais. Revista NECAT, 8(15), 35-43.

Löckenhoff, C. E., Terracciano, A., \& Costa Junior, P. T. (2009). Five-factor model personality traits and the retirement transition: Longitudinal and cross-sectional associations. Psychology and Aging, 24(3), 722-728.

Mendes, K. D. S., Silveira, R. C. C. P., \& Galvão, C. M. (2008). Revisão integrativa: método de pesquisa para a incorporação de evidências na saúde e na enfermagem. Texto \& Contexto - Enfermagem, 17(4), 758-764.

Muniz, J. A. (1996). PPA: Programa de Preparação para o Amanhã. Estudos de Psicologia (Natal), 2(1), 198-204.

Murta, S. G., Abreu, S., França, C. L., Pedralho, M., Seidl, J., Lira, N. P. M. et al. (2014). Preparação para a aposentadoria: implantação e avaliação do programa viva mais! Psicologia: Reflexão e Crítica, 27(1), 1-9.

Pazzim, A. T., \& Marin, A. (2016). Programas de Preparação para Aposentadoria: Revisão sistemática da literatura nacional. Revista Brasileira de Orientação Profissional, 17(1), 91-101. 
Rafalski, J. C., \& Andrade, A. L. (2017). Desenvolvimento da Escala de Percepção de Futuro da Aposentadoria (EPFA) e Correlatos Psicossociais. Psico-USF, 22(1), 49-62.

Rodrigues, M., Ayabe, N. H., Lunardelli, M. C. F., \& Canêo, L. C. (2005). A preparação para a aposentadoria: o papel do psicólogo frente a essa questão. Revista Brasileira de Orientação Profissional, 6(1), 53-62.

Scorsolini-Comin, F. (2015). Aconselhamento psicológico: Aplicações em gestão de carreiras, educação e saúde. São Paulo: Atlas.

Scorsolini-Comin, F., Rossi, G. A. N., Curtiço Junior, J. H., Costa, L. M., Silva, L. D. R., \& AlvesSilva, J. D. (2019). Adoecimento e aposentadoria: Relato de uma experiência profissional em aconselhamento psicológico. Revista Psicologia e Saúde, 11(2), 83-98.

Soares, D. H., Luna, I. N., \& Lima, M. B. (2010). A arte de aposentar-se: Programa de preparação para aposentadoria com policiais federais. Estudos Interdisciplinares sobre o Envelhecimento, 15(2), 293-313.

Vuori, J., Toppinen-Tanner, S., \& Mutanen, P. (2012). Effects of resource-building group intervention on career management and mental health in work organizations: Randomized controlled field trial. Journal of Applied Psychology, 97(2), 273-286.

Zanelli, J. C. (2012). Processos psicossociais, bem-estar e estresse na aposentadoria. Revista Psicologia, Organizações e Trabalho, 12(3), 329-340.

Recebido em: 28/05/2019

última revisão: 20/07/2019

Aceito final: 10/09/2019

\section{Sobre os autores:}

Natalí Andrade da Cunha: Psicóloga pela Universidade Federal do Triângulo Mineiro (UFTM). E-mail: psicologanatali@gmail.com, Orcid: https://orcid.org/0000-0002-5733-6600

Fabio Scorsolini-Comin: Psicólogo, doutor, mestre e livre docente em Psicologia pela Universidade de São Paulo (USP). Professor associado do Departamento de Enfermagem Psiquiátrica e Ciências Humanas da Escola de Enfermagem de Ribeirão Preto da USP. E-mail: fabio.scorsolini@usp.br, Orcid: https://orcid.org/0000-0001-6281-3371

Raquel Cornélio Marin: Psicóloga pela Universidade Federal do Triângulo Mineiro (UFTM). E-mail: raquelcmarin@hotmail.com Orcid: https://orcid.org/0000-0002-3102-2304 